\section{Ascent of Calcium in Intact and De-rooted Bean Plants}

CALCruM ions are known to be practically immobile in the phloem of plants and are thus not re-translocated from older leaves ${ }^{1}$. Other elements manifesting low phloem mobility are zine, boron and iron; the lastmentioned is also immobilized in the xylem in various circumstances $^{2}$. Apparently, it has not been suggested that elements other than iron may be immobilized in the xylem $^{2}$.

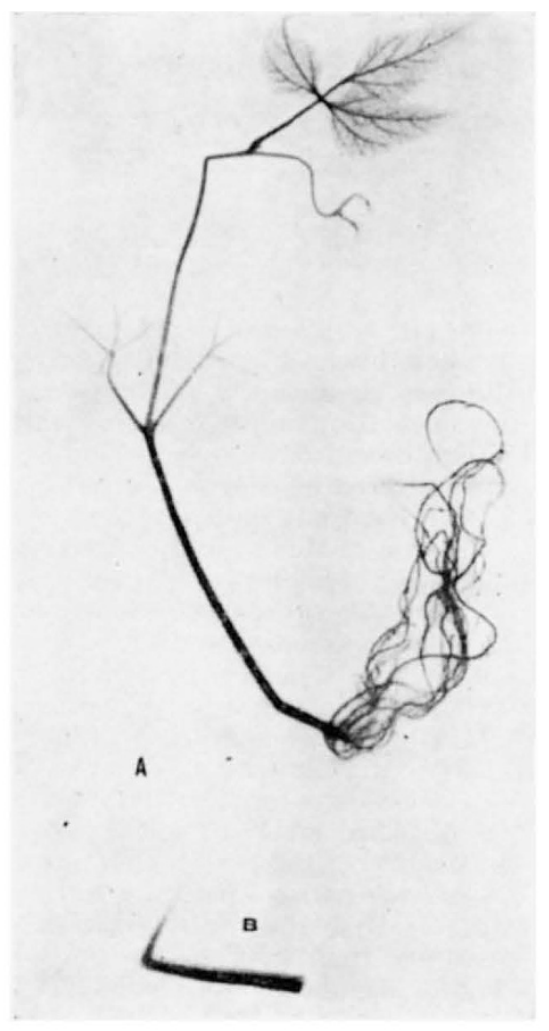

Fig. 1. Autoradiographs of $(A)$ intact bean plant, and $(B)$ similar but de-rooted bean plant. Both absorbed calcium-45 from a labelled $10^{-3} \mathrm{~T}$ calcium chloride solution during $24 \mathrm{~h}$, at $25^{\circ} \mathrm{C}$, in a photoperion of $18 \mathrm{~h}$ light and $6 \mathrm{~h}$ darkness

In the present investigation, upward movement of calcium in de-rooted and in intact bean plants (Phaseolus vulgaris L.) was compared. Calcium was delivered to the whole plant when absorbed by roots of intact plants; it was, however, rotained in the basal stem segment when absorbed by cut surfaces of similar but de-rooted plants (Fig. 1). Other mineral ions such as chloride ${ }^{3}$, sulphate and potassium, as well as an acid dye-fuchsinwere found to be distributed throughout the whole plant when absorbod by de-rooted beans. Immediate microscopic examinations of hand-sections made from stems of de-rooted plants after absorption of acid fuchsin showed that the flow of the solutions was restricted to the xylem vessels. These observations seem to indicate that the mobility of calcium ions in the xylem vessels of bean plants is increased by the passage of these ions through the roots.

Iron chelates have been found in exudates from soybean ${ }^{4}$ and tobacco ${ }^{5}$ plants; it was therefore suggested that chelated iron is the form translocated in intact plants. The effect of bean roots on the mobility of calcium ions in tho xylem may also result from the binding of these ions to organic ligands during permeation of the roots, and thus translocation in the xylem as metal organic calcium compounds. This hypothesis seems to be con- firmed by further experiments, the results of which will be published in detail elsewhere.

Department of Plant Physiology,

B. JACOBY

The Hebrew University,

Rehovot, Israel.

'Biddulph, O., in Plant Physiology, edit. by Steward, F. C., 2, 553 (1959).

"Bollard, E. G., Ann, Rev. Plant Physiol.,11, 141 (1960).

${ }^{3}$ Jacoby, B., Plant Physiol., 39, 445 (1964).

' Shmid, W. E., and Gerloff, G. C., Plant Physiol., 36, 226 (1961).

s Tiffin, I. O., and Brown, J. C., Science, 135, 311 (1962).

\section{RADIOBIOLOGY}

\section{Roles of Phosphate and Respiration in Nuclear Damage in Irradiated Rat Thymocytes}

The highly radiosensitive thymic lymphocyte (or thymocyte) suffers true physiological death shortly after irradiation with relatively low doses of X-rays. The most striking symptom of radiation damage is the loss of nuclear structure (pycnosis); the prominent ehromatin granules and threads of the interphase nucleus disperse and form a structurally homogeneous basophilic mass ${ }^{1}$.

The development of nuclear homogeneity is prevented, or reduced, by the inhibition of respiration eithor with inhibitors such as cyanide and high concentrations of nicotinamide, or by incubating the irradiated cells in an anaerobic environment ${ }^{2,3}$. Changing the phosphate concentration of the medium also has a profound effect on the post-irradiation rate of nuclear homogenization ${ }^{1,4}$ This communication describes the relationships between respiration rate, phosphate concentration and nuclear structural homogenization (pycnosis). It also presents evidenco to support the hypothesis that nuclear homogenization is caused by phosphate.

Thymoeytes (from 1-month-old Sprague-Dawley rats) were suspended in a glucose-phosphate medium buffered at $p \mathrm{H} \quad 7 \cdot 2$ with tris (hydroxymethyl) aminomethane. Phosphate was added in the form of sodium monohydrogen phosphate, and variation of its concentration required that the concentration of sodium chloride also be varied to keep the total $\mathrm{Na}^{+}$concentration at 130 m.equiv./l.; the rate of nuclear homogenization is strongly influenced by the concentration of sodium ions ${ }^{1}$. This medium and the method of preparing thymocyte suspensions have already been described in full ${ }^{1,2,4,5}$.

Thymocyte suspensions were irradiated at $37^{\circ} \mathrm{C}$ with $1,000 \mathrm{r}$. (at $100 \mathrm{r}$. $\mathrm{min}^{-1}$ ) of $250 \cdot \mathrm{kV} \mathrm{X}$-rays produced by a Seifert 'Isovolt' $X$-ray machine. After irradiation, $2 \mathrm{ml}$. samples were removed from the suspensions (containing about $1 \times 10^{8}$ cells $/ \mathrm{ml}$.) and placed in respirometer flasks. After irradiation, oxygen consumption was measured for $2 \mathrm{~h}$ with a Warburg constant volume respirometer. The gas phase in the flasks was air. The cells were then fixed in neutral formalin and stained with Delafield's haematoxylin according to the method developed by Whitfield et al. ${ }^{1}$.

The relation between respiration rate and nuclear homogenization was determined by suspending irradiated cells in medium containing $15 \mathrm{mM}$ sodium monohydrogen phosphate and varying their respiration rate by incubating them at various temperatures from $25^{\circ}$ to $37^{\circ} \mathrm{C}$. The rate of nuclear homogenization was very sensitive to changes in the respiration rate between 8 and $24 \mu \mathrm{l}$. oxygen consumed per $10^{8}$ cells/h (Fig. 1). When the oxygen consumption fell below $8 \mu \mathrm{l} . / 10^{8}$ cells $/ \mathrm{h}$, the deve!opment of nuclear homogeneity was completely inhibited.

Therefore, when the phosphate eoncentration is constant, the rate of nuclear homogenization is determined by the respiration rate. However, experiments with 2,4dinitrophenol clearly showed that respiration itself was not dircetly responsible for the nuclear changes. When dinitrophenol was added to cell suspensions (in $15 \mathrm{mM}$ phosphate medium; incubated at $37^{\circ} \mathrm{C}$ ) at a concentretion 